\title{
Urbanismo y ecología en Buenos Aires: un recorrido por la planificación urbana en su contexto ecológico-regional
}

\author{
Planejamento e ecologia em Buenos Aires: um passeio de planejamento \\ urbano em seu contexto ecológico-regional
}
Urbanism \& ecology in Buenos Aires: an overview throughout urban planning journey inside its regional context

Leonardo Fernández

Universidad Nacional de General Sarmiento, Instituto del Conurbano, Los Polvorines, Buenos Aires, Argentina

\section{Resumen}

La urbanización de Buenos Aires, inserta en un contexto pampeano y rioplatense, significó la construcción de un espacio metropolitano de notable densidad poblacional: en las últimas cinco décadas la superficie urbanizada llega a duplicar la huella de toda la historia urbana de 430 años. Este trabajo vincula conceptualmente "urbanismo y ecología", específicamente, trazando líneas de pensamiento principales en el desarrollo disciplinar del urbanismo argentino (por ejemplo, el funcionalismo de Le Corbusier y el organicismo de Della Paolera) y su relación con el crecimiento urbano de Buenos Aires. Recorremos ciertos elementos teóricos de dominio biológico, que caracterizaron la impronta de la planificación urbana. Se subraya la dimensión metropolitana en torno al concepto de región sintetizando a lo largo del tiempo el crecimiento hacia la pampa y hacia el Río de la Plata. A modo de cierre, el concepto "urbanismo ecológico" se sitúa en Buenos Aires recorriendo sintéticamente las principales implicancias ecológicas de la urbanización actual.

Palabras-clave: Urbanismo. Buenos Aires. Ecología.

\section{Resumo}

A urbanização de Buenos Aires, inserida em um contexto pampiano e rio-platense, significou a construção de uma área metropolitana de notável densidade populacional: nas últimas cinco décadas, a área construída atinge o dobro do registrado em seus 430 anos de história urbana. Este texto está situado em Buenos Aires, percorrendo a origem do urbanismo e sua relação com a ecologia, especificamente, o desenho de linhas de pensamento no principal disciplina do planejamento urbano argentino (por exemplo, o funcionalismo de Le Corbusier e organicismo de Della Paolera) e sua relação com o crescimento da cidade de Buenos Aires. Destacamos a faceta metropolitana o crescimento de Buenos Aires em torno ao conceito de região é sintetizada, ao longo do tempo no contexto pampiano e rio-platense. Para concluir, o conceito de "urbanismo ecológico" está localizado em Buenos Aires sinteticamente através das principais implicações ecológicas da urbanização atual.

Palavras-chave: Urbanismo. Buenos Aires. Ecologia.

LF es Ecólogo urbano/urbanista; Profesor adjunto e investigador, Instituto del Conurbano, Universidad Nacional de General Sarmiento, e-mail: lfernand@ungs.edu.ar 


\begin{abstract}
Buenos Aires urbanization, inserted in a pampeano and rioplatense context, resulted in the development of a metropolitan area with significant population density. Over the last five decades the occupation of urban land even double the entire urban history of 430 years. This article aims to analyze the emergence of urbanism in Buenos Aires and its links with ecology, studying the origins of the urban planning discipline in Argentina (eg, Le Corbusier's functionalism and Della Paolera's organicism) and its relationship with the urban growth in Buenos Aires. Throughout the article we examine in which way the inclusion of some cognitive supports linking the city with the biological language operates. We underline the Metropolitan dimension around the region concept, that synthesizes the growth toward the pampa and the Río de la Plata river. To conclude, the "ecological urbanism" as a concept is introduced in Buenos Aires with slogans to plan and manage the city. In this regard, we propose the approach of the city as an ecosystem, revising synthetically the main implications of current urbanization.
\end{abstract}

Keywords: Urban planning. Buenos Aires. Ecology.

\section{Introducción: la emergencia del urbanismo en Buenos Aires}

La historia de la urbanización de Buenos Aires, atravesada por procesos de orden político, económico y social, supuso la construcción de un espacio metropolitano de notable densidad poblacional. Hoy en día, en la Región Metropolitana de Buenos Aires, inserta en un contexto pampeano y rioplatense, habitan cerca de 15 millones de habitantes, que representan el $37 \%$ de la población del país en un entorno urbanizado de $2.500 \mathrm{~km}^{2}$, menor al $1 \%$ del territorio nacional (INDEC, 2010) ${ }^{1}$. Un impulso a la concentración urbana en la interfase continental y estuarina, con una transformación del entorno natural y rural que alcanza un marco físico extraordinario: sólo en las últimas cinco décadas la ocupación de suelo urbanizado llega a duplicar toda la huella urbana de 430 años, iniciada en 1580 con la fundación de Juan de Garay.

Bien podríamos rastrear con el texto vínculos entre urbanismo y ecología, específicamente, reuniendo aquellos precursores teóricos y prácticos, que hacia finales del siglo XIX y principios del XX se preocuparon, entre otras cosas, de los efectos que la industrialización y el fenómeno de urbanización,

\footnotetext{
${ }^{1}$ Este espacio involucra a la Ciudad Autónoma de Buenos Aires y 40 partidos del entorno metropolitano en la Provincia de Buenos Aires. Datos del Censo Nacional de Población, Hogar y Vivienda 2010, realizado por INDEC (2010).
}

sin precedentes en la época, provocaban en el medio físico de las ciudades. Es el auge de la profesión de urbanistas, que empiezan a celebrar congresos, a publicar revistas y abrir cátedras, e incluso también, a institucionalizar el urbanismo como una disciplina autónoma que se encargará, de aquí en adelante, de elaborar planes con los que abordar los problemas de la urbanización.

En Buenos Aires el desembarco del urbanismo como disciplina va a signar acuerdos con instituciones dentro del aparato estatal con el ensayo de planes para regular el crecimiento urbano (Novick, 2007) ${ }^{2}$. El enorme proceso de urbanización -digamos desde la federalización de Buenos Aires- se liga a un flujo de población migratoria, en la medida que la ciudad pasa a ser un gran polo de atracción, por su marco geográfico, por el proceso de industrialización, por el tipo de desarrollo de su infraestructura portuaria y de comunicación... e incluso por las dificultades que había para acceder a la tierra rural, las cuales fueron, indudablemente, algunas de las razones que explican el impresionante grado de implantación urbana.

El comienzo de la inmigración masiva es decisivo para el ascenso del urbanismo, sobre todo cuando se delinea un cambio en la fisonomía de la ciudad. El alto

\footnotetext{
${ }^{2}$ Tema tratado ampliamente por Novick (2007). Seguimos su planteamiento para estudiar la ciudad a través de los planes urbanos, ya que dan cuenta de formas de pensar y actuar sobre la misma y, más allá de su concreción efectiva, han dejado su huella en el territorio.
} 
crecimiento demográfico del país, desde fines del siglo XIX, estuvo fuertemente relacionado con flujos migratorios externos de ultramar impulsados desde el estado, que implica una extraordinaria expansión física de la ciudad. Pero es hacia finales de la década de 1920 que se da otro flujo migratorio, esta vez interno y proveniente del campo, fundamentalmente encarnado por los llamados "cabecitas negras", quebrachales, proveniente de las zafras, los ingenios azucareros, como consecuencia de la crisis de las economías regionales, por efecto de la Gran Depresión de 1929. En ese contexto, Buenos Aires, inmersa en un proceso de industrialización sustitutiva de los puertos, en frigoríficos, a las fábricas textiles, en playones ferroviarios, llega a alcanzar una urbanización vertiginosa, y, con ello, altos niveles de hacinamiento, miseria y contaminación.

La región crece como "dedos" basados en patrones de urbanización rectores: las líneas de ferrocarril organizan el crecimiento urbano, mientras que alrededor de la estructura de centros se desarrollan las estaciones del tren. Este patrón fue de la mano de la geografía - la costa y las cuencas - y de las infraestructuras del transporte - el ferrocarril y los caminos -, llegando a configurar una fisonomía radial. En todo ese trayecto de Buenos Aires, tanto dentro como fuera de los límites de la Avenida General Paz y el Riachuelo, va incorporándose un enorme tejido residencial a través de la urbanización de las quintas existentes. La descontrolada especulación de los dueños de la tierra se materializaba aumentando el rendimiento de los loteos y anulando, casi totalmente, las antiguas reservas verdes, de chacras, quintas, incluso de los centros de las manzanas, con los que se conformará el Conurbano Bonaerense. Y hecha esa mención toponímica, aunque se desconozca su acuñamiento, no podemos dejar de soslayar su filiación con el biólogo irlandés Patrick Geddes, quien usa la palabra "conurbación" en Cities in Evolution (Geddes, 1915) para referirse a la expresión material del aglutinamiento poblacional aparejada por la agregación de varios núcleos urbanos preexistentes, tal como efectivamente se venía gestando desde hacía tiempo en Buenos Aires.

En tan solo algunas décadas, desde los conventillos en el casco histórico hasta los loteos extendidos en la periferia -conectados por tranvías, ferrocarriles y colectivos -, se produce un enorme crecimiento demográfico: 170.000 habitantes en 1870 , que se multiplicará por ocho en 1914, hasta alcanzar aproximadamente los 4.000.000 en 1936. La nacionalización de los ferrocarriles, como menciona Torres (1993), es determinante en la expansión física de la aglomeración pues la transformación de suelo urbano insumía tiempo de los trabajadores en sus desplazamientos a los centros de empleo. El transporte colectivo desde los años ' 40 es otro factor que estructuró la organización suburbana, en particular la ocupación de intersticios entre ejes ferroviarios. En la periferia, con unas áreas residenciales de baja densidad demográfica, surgen viviendas autoconstruidas que carecen de servicios urbanos de alta demanda social como agua, cloacas, pavimentos, redes pluviales y recolección de residuos (Clichevsky et al., 1990). Un recorrido desde el centro a la periferia bonaerense, va reflejando que la ciudad se vuelve progresivamente más precaria, constatando en su periferia un retraso en la construcción de redes de infraestructura, transporte y espacios públicos. La mayoría de la población lograba un lote para construir su vivienda, sobre todo en la periferia, pero muchos no accedían a la tierra e iban buscando una alternativa, terminando por instalarse en terrenos fiscales o vacantes, debajo de los puentes ferroviarios o en baldíos muy céntricos, dando lugar a un fenómeno de multitudes: la villa miseria.

Ahora bien: en el origen del urbanismo argentino, influido por corrientes europeas aunque traducidas y reelaboradas a nuestro contexto geográfico, es posible reconocer una preocupación ecológica (Caride, $2013)^{3}$. Esta idea tuvo expresión en el planeamiento urbano de Buenos Aires, de la mano de urbanistas nacionales e intercambios con especialistas de renombre internacional, con capacidad técnica y reconocimiento social, con definidas posturas doctrinarias e ideológicas, muchas veces antagónicas y otras veces cercanas en sus planteos, en sus trayectorias profesionales, aunque también en sus alianzas políticas.

Realizaremos algunos apuntes en relación a la historia cultural urbana que, como objeto de estudio, privilegian las representaciones sobre la ciudad, adoptando problemas, temas y matices diversos, de diferentes maneras: marcando cómo la ciudad y sus representaciones se producen mutuamente (Gorelik, 1998), revalorizando el rol de los técnicos y funcionarios estatales en la concepción y modos de intervenir en

\footnotetext{
${ }^{3}$ Tomamos como derrotero el vínculo entre biología y planes para el Gran Buenos Aires sistematizado por Horacio Caride (2013).
} 
la ciudad (Liernur, 2001), o confrontando ideas y prácticas a la hora de analizar cómo se plasman los proyectos y planes para la ciudad (Novick, 1992), por destacar algunos abordajes de interés. Y aún más: la historia cultural de la ciudad plantea una "tensión de enfoques", en la perspectiva de Gorelik, que supone el ejercicio de interrogar, colocar en perspectiva y ofrecer puntos de vista en dimensiones intelectuales, figurativas y representacionales sobre las ideas de la ciudad, incluso sobre cómo la ciudad real se va conformando, a su vez, como producto de dichas ideas. En ese recorrido realizamos una lectura de los vínculos ecológicos de las principales líneas del urbanismo, objeto de este texto.

\section{Organicismo versus funcionalismo}

Apelando a las terminologías que conceptualizan las referencias principales del urbanismo moderno, fundamentalmente las expresadas en los planes urbanos para Buenos Aires y su región, sería posible reconocer dos líneas de pensamiento: la vinculada con el «funcionalismo» o estilo internacional en la arquitectura, que viene de la mano de Le Corbusier (pero también adelantada aquí con Bereterbide \& Vautier $^{4}$ ) y el movimiento moderno ligado al CIAM (Congreso Internacional de Arquitectura Moderna); y en contrapartida, la del "organicismo", que en la

\footnotetext{
${ }^{4}$ La caracterización de Vautier y Bereterbide como exponentes del funcionalismo no estaría exenta de debates. Sin embargo, es posible encontrar claras referencias de esa doctrina urbanística en sus textos, como lo expresa un apartado denominado "Zonización" del texto citado: «Una ciudad, por el hecho de ser una organización humana creada para una finalidad determinada, puede ser equiparada a una máquina y, como tal, debe ser racionalizada de acuerdo a sus funciones. El orden incipiente y confuso que anima su vitalidad (producción, administración, consumo) debe ser depurado, relacionándolo con los hechos de circulación que el intercambio y la producción han originado, y con la formación de zonas residenciales (y de consumo), organizando la ciudad para el trabajo y el reposo de sus habitantes». De todos modos, hay marcadas evidencias de cierta intención de aunar enfoques, matizando conceptos organicistas como "evolución", "organización” y "naturaleza”, propias del organicismo (Vautier y Bereterbide, ob. cit., 1932, p. 42.; las cursivas son del autor). En algún sentido, podría asociarse en Vautier y Bereterbide cierta ideología arquitectural ligada al funcionalismo, aunque con un posicionamiento urbanístico que conjuga elementos funcionalistas y organicistas (Vautier \& Bereterbide, 1932).
}

historia del urbanismo argentino está ligado a la figura de Carlos María Della Paolera (y que tiempo después, contara con un desarrollo prolífico de Patricio Randle), ecuménico del urbanismo argentino, discípulo del francés Marcel Poëte, que entendía la ciudad como un "cuerpo" urbano y la historia en clave "evolutiva" (Figura 1).

Esa línea funcionalista encabezada por Le Corbusier está atravesada por el concepto de la "ciudad como máquina". Desembarca en Buenos Aires mientras se encuentra en ebullición una industrialización sustitutiva, con un éxodo de población migrante del campo a la ciudad. Una época en que la guerra en Europa destruía ciudades, mientras que en América, al ritmo de una vertiginosa industrialización, las construía. Eran tiempos de recesión mundial y, por tanto, de déficit en la producción de bienes y servicios, algo que se haría patente en la arquitectura: racionalizando los métodos de edificación y desplegando el taylorismo en la construcción. Naturalmente esa idea se manifiesta en el terreno del urbanismo, donde resurge el concepto de "zonificar", por analogía con la racionalización del sistema de producción industrial: división de trabajo en la cadena de montaje, y división de las funciones en las zonas de la ciudad. Desde esta noción, análoga al fordismo, se supervisa por separado cada paso del proceso de producción: en la ciudad, a través de la zonificación, cada función urbana se realiza en un lugar específico de su territorio. De ahí las cuatros funciones fundamentales que hay que especializar: "habitar, trabajar, recrear y circular". Funciones que pretendidamente convierten a la ciudad en una ingeniería de cuerpos en movimiento que se igualan al tránsito de una cadena de montaje de una fábrica.

Por otro lado está esa otra línea en la historia del urbanismo, iniciada con Geddes y Sitte, y proseguida aquí con Della Paolera y Karman, con una visión "organicista de la ciudad"; es decir, la ciudad vista como un organismo vivo, cuyas funciones tienen correspondencia con la biología animal. La ciudad es concebida orgánicamente, en tanto está integrada a diferentes partes, las cuales se coordinan para cumplir diferentes funciones: el "sistema circulatorio" de la ciudad está constituido por calles y avenidas, que trabajan como arterias y venas; este sistema lleva y distribuye las substancias necesarias para la vida a todos los puntos del cuerpo urbano; el "corazón" es el centro de la ciudad, el punto donde convergen las calles y avenidas por donde se circula; el "sistema 


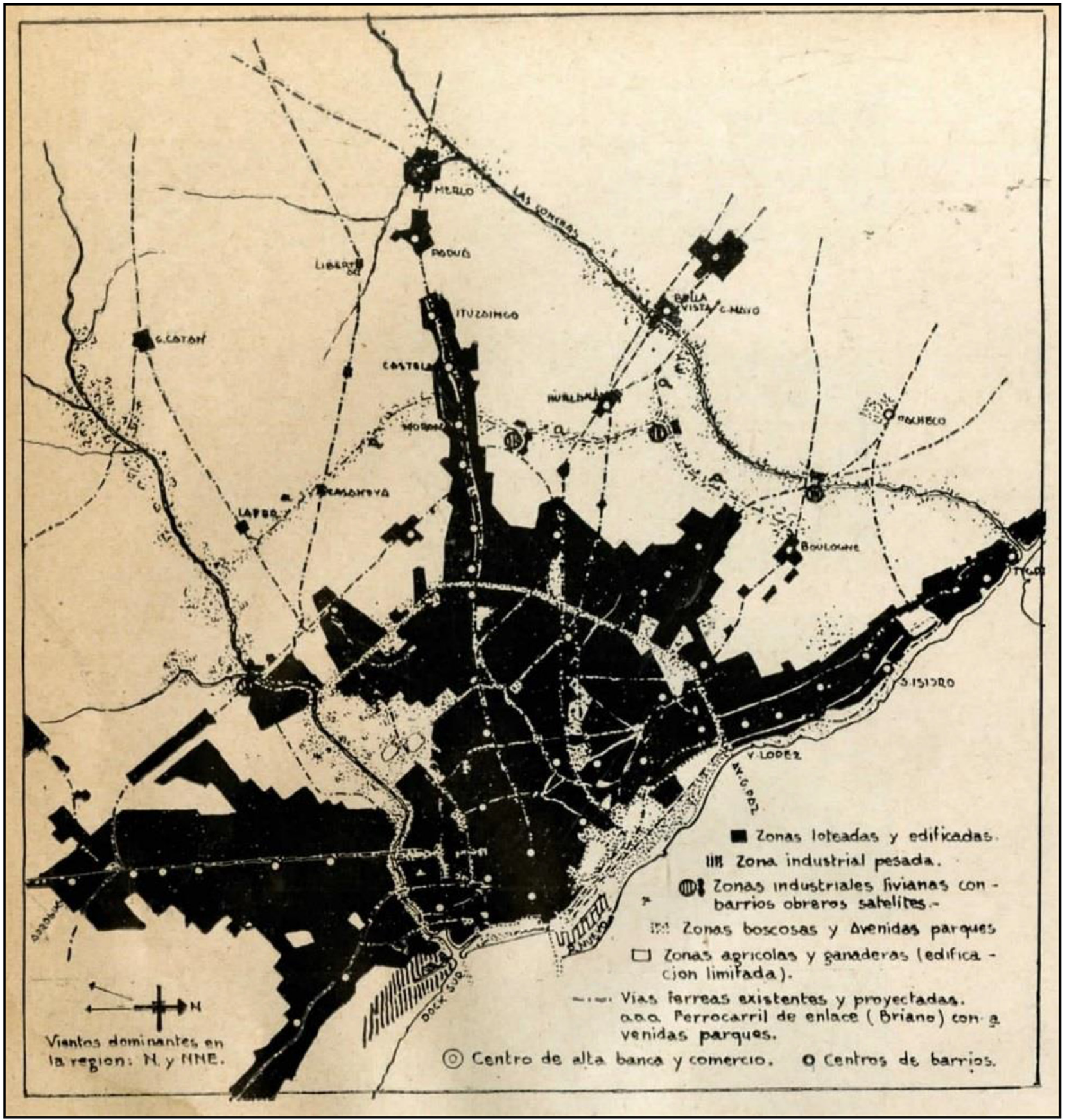

Figura 1 - Esbozo para un Plan Regional de Buenos Aires, 1932. Escriben Vautier \& Bereterbide (1932): el límite de la zona actualmente loteada (mancha negra) debe ser el límite definitivo del Gran Buenos Aires, el cual ya no debe extenderse más ocupando los espacios libres. La zona comprendida dentro de este límite (con una capacidad para una población de 10 millones) debe ser remodelada paulatinamente en loteo, tipo de edificación, vialidad y espacios libres, de acuerdo con las directrices del urbanismo contemporáneo Fuente: Carlos María Della Paolera. Oficina del Plan de Urbanización (Della Paolera, 1932 apud Vautier \& Bereterbide, 1932).

muscular" representa la red eléctrica (y la red de gas) abasteciendo la energía necesaria para la industria y su sistema de transporte; los "pulmones" de la ciudad son sus espacios libres: avenidas, plazas, jardines, parques, campos de juegos, etcétera; de la misma forma que las células extraen el oxígeno del cuerpo humano a través del contacto con las venas del sistema arterial, las casas reciben el aire y la luz, indispensable para su sanidad, a través de la apertura de sus ventanas; las redes de agua y cloacas (alcantarillado) son comparables a los 
"órganos digestivos"; así como los grandes mercados de aprovisionamiento constituyen el "estómago" de la ciudad (Oliveira, 1940 apud Outtes, 2002).

Pero volvamos con el funcionalismo. Para Le Corbusier el urbanismo es una técnica en acción. En la introducción del Plan Director advierte: "Buenos Aires, la ciudad destino de Sudamérica, está más enferma que ninguna". Cuando la conoció, en su viaje de 1929, la llamó "la ciudad sin esperanzas" porque en su planteo, los efectos que la industrialización arrojaba sobre la ciudad no dejaría en el medio físico "ni aún la esperanza", a menos que "reaccione y actúe", que considere su "mal como crisis de crecimiento", que admita "una metamorfosis [que] transforme su destino". Y esa noción de metamorfosis condensa una idea que debía interpretar el urbanismo, ligado a un "fenómeno natural de crecimiento", cuyas condiciones eran: "primero la fuerza, luego la geografía, después la topografía y después la palanca irresistible de las posibles valorizaciones" de la tierra urbana. Justamente, pasaron años de la visita de Le Corbusier hasta que en 1937, junto a los arquitectos argentinos Ferrari Hardoy y Kurchan, establecieran el Plan Director de la Ciudad de Buenos Aires. Un plan urbano, elaborado en su taller parisino durante un año de trabajo, basado en una Ville radieouse bonaerense: la topografía, la arquitectura y sus formas lo son todo, donde ganan protagonismo rascacielos agrupados y rodeados de parques y vías de tránsito. Un urbanismo que pone al suelo en perspectiva tridimensional, para organizar los edificios y la comunicación, bien impreso en la iconográfica Cité des Affaires, en una visión terrenal (de un estuario aunque en rigor Le Corbusier lo pensara como un mar) y aérea respecto al centro de la ciudad de Buenos Aires (Figura 2).

Mucho antes, la Comisión de Estética Edilicia realiza el Proyecto Orgánico para la Urbanización del Municipio (1925), con una concepción humanística de la ciudad, tal como Camilo Sitte o Raymond Unwin, incluso Werner Hegemann, recuperando una vertiente más próxima a la "ciudad jardín" (Buenos Aires, 1925). Ya desde el título se registra que la idea "orgánica" es entendida como una relación entre las partes y el conjunto, con una propuesta de intervenciones parciales, destacando el sentido organizador del espacio público. Basado en el "arte urbano", característico del academicismo francés, incluye proyectos como la valorización del contacto con el río con una costanera, la reestructuración vial, la cualificación del centro,

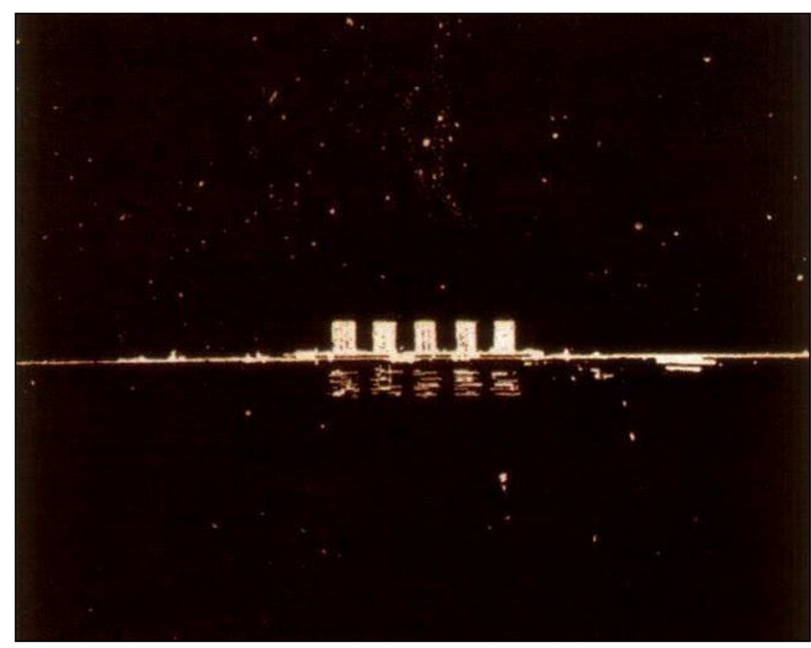

Figura 2 - Cité des Affaires. Croquis de los Cité des Affairesen Buenos Aires sobre la línea rioplatense y la infinitud de la Pampa. La extensión de la llanura de Buenos Aires resumida en el dibujo nocturno de los rascacielos cartesianos, cuya luminosidad identifica el encuentro del denso Río de la Plata con el profundo cielo estrellado bonaerense Fuente: Le Corbusier et al. (1947).

la ampliación de espacios verdes, expansión de los servicios sanitarios y consideraciones del crecimiento urbano, y por tanto, la propuesta de un nuevo ensanche para Buenos Aires, tal como ocurriera con Belgrano \& Flores.

Tiempo después Della Paolera, al frente de la Oficina de Urbanización, adopta una metodología de trabajo inspirada en el modelo médico: estudiar la evolución de la ciudad - la anatomía, en paralelismo con la historia clínica - a través de exhaustivos diagnósticos (medio geográfico, trabajos históricos, estudios de humos), elaborar estudios estadísticos - la fisiología, que refiere a la constitución de un programa - (análisis censal y los estudios del volumen construido, de las actividades económicas y comerciales), y las propuestas espaciales -la clínica médica quirúrgica, contenidas en el "arte urbano" - que plantea la necesidad de la intervención (Novick, 2000) ${ }^{5}$. Della Paolera, marcado a fuego con sus estudios en París, propone la necesidad de considerar la "aglomeración bonaerense" con una visión de conjunto que, con triunfos y fracasos, llega

\footnotetext{
${ }^{5}$ En esta visión, el urbanista es el "médico" que efectúa el diagnóstico en base a una "historia clínica" (evolución urbanística) y concibe el "tratamiento" (plan) en el cual, ciertamente, deben estar las consideraciones estéticas. La meta es el "organismo sano", modelo ideal al que se debe arribar mediante la conjunción del "arte y de la ciencia" (Novick, 2000).
} 
a plasmar la Avenida 9 de Julio como park-way de escala regional, vinculada con el sistema de parques de Forestier. Además, la construcción de tres puentes sobre el Riachuelo - puentes Avellaneda (1935), Uriburu (1938) y de la Noria (1941) - que posibilitaron desde entonces la vinculación entre la Capital y los municipios del sur.

\section{Los elementos naturales del urbanismo}

Venimos diciendo que hubo básicamente dos urbanismos en el origen del planeamiento para Buenos Aires. Está ese urbanismo de Le Corbusier, también en Vautier-Bereterbide y el grupo Austral, que es tábula rasa, recto, nihilista, tecnicista, industrialista. Aunque señalamos que ya su viaje de 1929, tal como escribe Segre (2006), supuso el cierre de una etapa platónica y purista de su lenguaje urbanístico basado en la "estética de la máquina" y la apertura a una dimensión geográfica, así como la adopción de elementos orgánicos y regionalistas en las pequeñas obras realizadas durante la década de los años treinta. Tal vez tuviera el convencimiento de que la ciudad debía contemplar el paisaje pampeano y rioplatense, ya no con la vocación de una ciudad industrial sino financiera, reposando en la tecnología que materializaba la arquitectura moderna de ese momento. Le Corbusier en Sur les quatre routes (Le Corbusier, 1941) escribe: “[...] el sol y la topografía son los elementos más importantes para hallar la profunda línea de cada civilización. Estos son los factores inmanentes que regirán todos los planes". La abstracción pura y la utopía por la civilización maquinista van cediendo a una cambiante realidad social, política y económica, donde lo ecológico va a definir nuevos parámetros desde donde puedan resolverse los problemas urbanos.

El funcionalismo logra plasmar una formulación muy concreta con la llamada Carta de Atenas ${ }^{6}$ de 1933. Allí se propone una serie de principios urbanísticos y realizaciones prácticas, donde se señala que el

\footnotetext{
${ }^{6}$ La Carta de Atenas es un manifiesto urbanístico redactado durante el IV Congreso Internacional de Arquitectura Moderna (CIAM) en 1933, y no sería publicado hasta 1942 por Sert y Le Corbusier. Originalmente el congreso iba a celebrarse en Moscú pero, por problemas con la organización soviética, se llevó adelante a bordo del crucero Patris II en la ruta Marsella-Atenas-Marsella; de ahí la denominación del manifiesto.
}

urbanismo no debe resolver exclusivamente el tema de la circulación mientras se erigen edificios como islotes dispersos, sino que se deben proponer las cuatro funciones: 1) facilitar un sano alojamiento (aire puro, sol y espacios verde para las viviendas), 2) organizar dignamente los lugares de trabajo, como una actividad humana y natural, no como penosa servidumbre, 3) articular el espacio del ocio para que sea benéfico y fecundo, y 4) crear una red de interconexión de las anteriores funciones a través de una red circulatoria. De esta manera, al hablar de la Carta de Atenas, se evoca todo el movimiento ideológico, tecnocrático y artístico que lo sustenta y que está, de alguna manera, encarnado en la figura de Le Corbusier. Él dirá: "[...] el urbanismo es una ciencia en tres dimensiones, y no dos dimensiones." Ahí reside una clave culturalista cuando argumenta que «es haciendo intervenir el elemento altura como se dará solución a las circulaciones modernas y a los esparcimientos, por el aprovechamiento de los espacios libres así creados (Le Corbusier, 1954) (Figura 3).

En contrapartida a esa visión urbanística encontramos en Della Paolera una ciudad orgánica, curva, romántica, culturalista, vernácula, preocupada por los problema de la "ciudad-carbón", expresión que connotaba la fábrica y la vivienda en íntima relación de promiscuidad y, a su vez, atravesada por el contexto regional, sobre todo, cuando piensa en la protección de suelo no edificable dedicado a la agricultura de proximidad, dándose una valoración del periurbano por los flujos de energía y materiales que sustenta la economía urbana. De ahí la propuesta de frenar la extensión de las conurbaciones en forma de "mancha de aceite", mediante la defensa de los "cinturones verdes". Ya para 1932, en el contexto de la creación de la Oficina del Plan de Urbanización, se realiza un planteo metropolitano presentado junto al alemán Hegemann y el argentino Kalnay. Posteriormente, Della Paolera esboza cuáles serían los elementos naturales para organizar las ciudades con la trilogía "aire, sol y vegetación”. Una síntesis quedó bien impresa en el texto escrito por Della Paolera, cuando crea la bandera del Símbolo del Urbanismo (Della Paolera, 1934).

Interesa señalar que en ese organicismo, regionalista, evolucionista de Della Paolera existe una ligazón con la noción alemana - casi ignorada - de Natürlich Entwicklung o "desarrollo natural" de la ciudad, tal como proponía Baumeister, acaso relacionado al viaje del alemán Hegemann en 1930, cuando se 


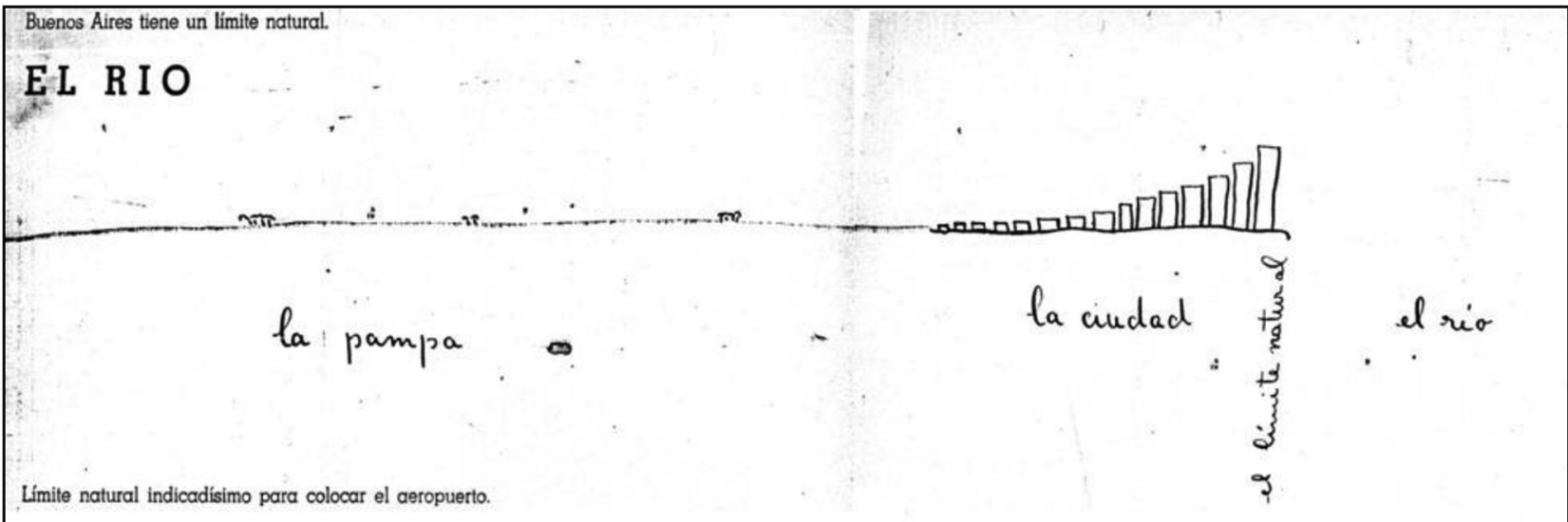

Figura 3 - Un aeropuerto en el Río

Fuente: Amancio Williams. "Proyecto de un aeropuerto en el río" (Le Corbusier et al., 1947).

trató en nuestra geografía el tema de la conurbación mediante un planteo contextual que integrara la popular y difundida autoconstrucción de viviendas en la periferia (Liernur, 1985). Aunque también se advierte una sugestiva retórica Blut und Boden (o "sangre y tierra") spengleriana. Idea manifiesta en el uso de la noción degeneración, de móvil eugenésico, que estaba muy presente en el escenario cultural sudamericano de comienzos del siglo veinte (Outtes, 2002). De acuerdo a esta representación, el hecho de vivir bajo precarias condiciones físicas suponía que las sucesivas generaciones serían cada vez más débiles, enfermas, incapaces de trabajar e inútiles para la sociedad. Y no olvidemos que la progresiva urbanización de la modernidad va trazando una visión en torno a la pobreza y el ascenso del proletariado industrial. Esta representación resulta tan influyente, que la idea es expresada en el panfletario folleto del "Símbolo del Urbanismo" (Della Paolera, 1934) (Figura 4) a través de la noción eugenésica opuesta de la regeneración: “[...] las generaciones futuras podrán apreciar los resultados del esfuerzo que ha prodigado el Urbanismo en esta cruzada de regeneración de las condiciones de vida de la sociedad humana [...]" (Della Paolera, 1934).

Aunque lo dicho resulte un tanto provocador, señalemos que hubo cierto biologismo en el abordaje de los temas de la ciudad, que contó no solo con la simpatía de socialistas y nacionalistas católicos, sino también de dictaduras. En la última dictadura (1976-1983), oligárquica y anti-industrialista, la cuestión social del urbanismo contenía imperativos represivos y asumía que vivir en ciertas condiciones urbanas - como una villa miseria - representaba una enfermedad que contaminaba el cuerpo social y, por tanto, había de ser erradicada. Sin embargo, en esa lectura del urbanismo organicista de Della Paolera también hay un higienismo y un esteticismo, inspirador de un cinturón verde para contención de la conurbación, tal como se ensayó a fines de la década de 1970, manu militari mediante, con el "cinturón ecológico" de Guillermo Laura y Jaime Smart (Laura, 1978), inclusive contando con el hijo de Della Paolera en sus filas. Este programa territorial se trató de una versión de reserva verde pública, algo basada en el green belts de Abercrombie, pero en este caso, como instalación de rellenos sanitarios, parques recreativos y una autovía de cintura (Della Paolera, 1981). Aunque, rigurosamente hablando, se impuso a caballo de la funcionalista -y costosa- "ciudad arterial", la de los trazados de autopistas (Laura, 1970).

\section{Urbanismo con planeamiento}

Podemos afirmar que en ambas líneas de planificación urbana hubo una inspiración ecológica desde modelos de ciudad muy diferentes, casi siempre enfrentados en torno a urbanistas disputando espacios profesionales, aunque -paradójicamente - tuviesen también muchos puntos de contacto. Encontramos un pensamiento que, desde la vereda de la arquitectura moderna, exaltó la industrialización, la técnica y la geometría; y otro que, desde la vereda del pensamiento romántico, artístico e histórico, lamentó la pérdida de paisajes vernáculos y se preocupó ante la destrucción de 


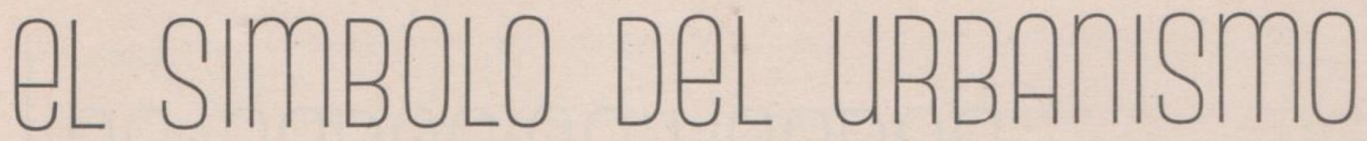

¡Aire, Sol, Vegetación! Tal es la trilogía de elementos naturales y esenciales para la vida humana, que se representan con el azul profundo, el astro rey y el verde veronés en el símbolo del urbanismo

- $\mathrm{N}$ esas colmenas humanas que son las grandes ciudades modernas se ha roto el equilibrio razonable entre la obra artificial y los elementos de vida que generosamente nos brinda la madre naturaleza. Siguiendo los más variados rumbos en sus investigaciones, los urbanistas de todo el mundo han llegado a la conclusión de que es necesario reconquistar el aire, el sol y la vegetación para el ambiente de la ciudad moderna. Las teorías y realizaciones urbanísticas más opuestas concuerdan en el objetivo final consistente en asegurar la unión íntima de la ciudad con la tierra viviente, dan. do amplia entrada a la naturaleza entre las masas inertes de la edificación urbana.

La ciencia is banistica moderna ha puesto plenamente en evidencia que la utilización en la ciudad de los más maravillosos e inesperados recursos de la técnica no debe ni puede excluir el

aprovechamiento intensivo de los elementos naturales. La ciudad como el árbol no puede des. ligarse de la tierra que la sustenta.

Durante mucho tiempo hemos creído, por una falsa asociación de ideas, que el progreso edilicio consistía en llenar con edificación todo terreno baldio. Pero de este error podemos por lo menos obtener una conclusión evidente y es que cuando la edificación compacta alcanza una extensión importante se produce en la ciudad un estado de desequilibrio que afecta profundamente la regularidad de sus funciones biológicas, vale decir, que hemos confundido progreso edilicio con desarrollo anormal o deformación patológica del organismo urbano.

El progreso urbano no consiste en invadir ciegamente los terrenos con la edificación sino en edificar conscientemente doride corresponde después de haber asegurado la formación y conservación del espacio en que debe dominar la naturaleza, facilitando la entrada del aire puro $y$ del sol vivificante al interior de las viviendas y de los barrios que se crean. Permitir que las viviendas de los seres humanos se amontonen desorganizadamente, en medio de las impurezas de un aire cargado de humo y gases deletéreos y produzcan así ambientes antihigiénicos y nocivos a la conservación y mejoramiento de la especie, significa incurrir en un anacronismo que contrasta violentamente con el grado de adelanto a que ha llegado la civilizacion.

Felizmente la reacción salvadora provocada por el Urbanismo en estos últimos tiempos no ha tardado en propagarse por todo el mundo. Luchando al comenzar contra la rutina y el escepticismo, los urbanistas quieren que la vida entre con el aire $y$ el sol en todas las viviendas $y$ que el niño se desarrolle y vigorice en ambientes propicios, en contacto intimo con los dones $y$ esplendores de la naturaleza. Todas las concepciones del Urbanismo moderno revelan esa preocupación fundamental. Desde la composición urbana de orden monumental hasta las más modestas organizaciones del tipo ciudad - jardín expresan, hoy claramente que los espacios verdes integran todas las nuevas creaciones urbanisticas $y$ penetran hasta en sus más sutiles ramificaciones como elementos de equilibrio de la obra artificial. Los sistemas de parques forman hoy, conjuntamente con las redes de tránsito, el esqueleto arquitectónico de la ciudad moderna. La reconquista de la ciudad por la naturaleza es una ofrenda promisora de salud y belleza para el hombre de la urbe. Las generaciones futuras podrán apreciar los resultados del esfuerzo que ha prodigado el Urbanismo en esta cruzada de regeneración de las condiciones de vida de la sociedad humana.

La Dirección del Plan de Urbanización de Buenos Aires, creyendo interpretar fielmente el sentir de todos los que se preocupan por el perfeccionamiento de las aglomeraciones humanas, ha reunido en un sencillo símbolo de comprensión universal la expresión de los elementos naturales que integran el indiscutido ideal urbanistico. Realizado este paso inicial confía en la solidaridad internacional de nuestra causa para propiciar su uso y colaborar en su divulgación.

CARLOS M. DELLA PAOLERA.

Figura 4 - El símbolo del urbanismo, 1934. La bandera, que consta de dos franjas horizontales, la superior de color azul profundo representa el "aire", el verde la "vegetación" y en el centro el "sol", realizada para enarbolar como un símbolo del urbanismo el día 8 de noviembre de cada año Fuente: Carlos María Della Paolera. Reproducción del manifiesto original del símbolo del urbanismo. Noviembre de (Della Paolera, 1934). 
edificios y estructuras de la ciudad burguesa. Estas dos corrientes son particularmente evidentes en las líneas de la técnica urbanística de Buenos Aires que, por un lado, a partir de los años 1930 y 1940, propugna un urbanismo promotor del automóvil y del bloque de edificios, y, por otro lado, un urbanismo que se opone a la destrucción de ambientes históricos y rurales, preocupado por el modo de expansión del conurbano bonaerense. Ambas líneas, destacadas en la década de 1940 y 1950, podrían vincularse y relacionarse con el contexto regional.

La oposición de la época "entre la ciudad y el conurbano" resulta patente en la planificación urbana. Los sucesos del "17 de octubre" de 1945 son una expresión identitaria del ascenso del peronismo, reivindicando el origen y la pertenencia de los sujetos sociales que lo encarnan y, por ende, el proyecto político en el territorio del conurbano. Es un contexto de reformas sociales profundas que deja en relieve al "Gran Buenos Aires" en clara oposición con la Capital Federal, al mismo tiempo que es un escenario de fuerte intervención del gobierno nacional, con la nacionalización de servicios públicos y el despliegue de un gran volumen de obra pública a través de los Planes Quinquenales. Subrayamos en el plano territorial y simbólico, por un lado, la "operación de Ezeiza", donde la política instala el aeropuerto internacional en el territorio bonaerense, algo así como "la puerta de entrada al país en la pampa", desplazando anteriores propuestas (como la del Plan Director de Le Corbusier) pensadas en las proximidades del Río de la Plata. Por otro lado, la "vivienda" popular se constituía en el ámbito privilegiado de la acción estatal, plasmada en cientos de planes habitacionales en los suburbios, entre ellos, el barrio jardín Ciudad Evita, un ícono de los "barrios peronistas" (Ballent, 2005, p. 230-231).

En esos años se destaca José Pastor, un ferviente sistematizador del urbanismo inglés y norteamericano, aunque más insistente a la hora de difundir una teoría propia de clara influencia germana. Introduce la noción de "Planeamiento" para cuestionar el "Urbanismo" estrictamente en la órbita de las ciudades, en términos municipales, antes que en el contexto regional al que pertenece, sentando las bases de un urbanismo ligado a la relación ciudad-campo propia del regionalismo alemán (Pastor, 1946). Su ejercicio profesional se despliega en muchos planes reguladores y en cursos impartidos a técnicos municipales, sobre todo, en la Provincia de Buenos Aires. Por otro lado, el EPBA
(Estudio del Plan de Buenos Aires) en el ámbito de la Ciudad de Buenos Aires, el grupo Austral (Antonio Bonet, Juan Kurchan y Jorge Ferrari Hardoy) - que marcó la arquitectura de vanguardia en los años cuarenta - y Amancio Williams, se destacaron en el impulso de un urbanismo formalista. El EPBA, más allá del corolario fallido de su accionar, logra plasmar un estudio marcado por la narración histórica en términos evolutivos y la formulación de operaciones ejemplificadoras a través de proyectos ${ }^{7}$. La influencia en el equipo de arquitectos de la ideología urbanística del regionalismo descentralizador de Lewis Mumford es notable, así como también la articulación con propuestas arquitectónicas corbuserianas (Gorelik, 2004, p. 130).

Décadas después destaca, en el desarrollo teórico, Patricio Randle, un intelectual de derechas, nacionalista católico, organicista en su concepción del urbanismo, con ideas en su voluminosa obra académica sobre el vitalismo de Von Uexküll (1945) adaptadas a las ciudades, específicamente en torno al concepto de "conformidad a plan" de los organismos vivientes. La "[...] analogía [biológica] no es mera alegoría [...] ", escribe Randle (1983, p. 64-65), en tanto se acepte que "la ciudad posea una causa final". En su obra se refiere a la geografía del paisaje y vincula el urbanismo de Geddes, Mumford y Poëte. Aunque nos interesa destacar una interpretación que hace para Buenos Aires con un soporte teórico alrededor del concepto de "hipertrofia", como característica de la evolución de la ciudad. En esta noción aparece conjugada la idea de "crecimiento anómalo" de la población urbana en relación al conjunto del territorio nacional y, por ende, una "razón de ser" del urbanismo (Randle, 1984, p. 45-84). Una figura cognitiva de inevitables vinculaciones con la política posterior.

Estas dos líneas de urbanismo estuvieron casi siempre enfrentadas, aunque más allá de esas dos actitudes la impronta principal finalmente reposó en la legislación urbanística, como la del Código de Planeamiento Urbano de la Ciudad de Buenos Aires. Fue Odilia Suárez la que había iniciado la elaboración de los textos entre 1971 y 1973, en un claro legado de los trabajos del Plan Regulador (1958-1965), que

\footnotetext{
${ }^{7}$ La investigación urbana que hacía el EPBA se publicará recién en 1955 y 1956 con el título "Evolución del Gran Buenos Aires en el tiempo y en el espacio" como separata especial de la Revista de Arquitectura", de la Sociedad Central de Arquitectos de Buenos Aires.
} 
apuntaba a un bloqueo de instalaciones industriales, de estabilización de la población de la ciudad y, como correlato, de un desplazamiento industrial y residencial hacia la periferia. Pero sobre las pautas urbanísticas del Plan Regulador, estaba la influencia que la Ciudad de Buenos Aires ejercía sobre toda su conurbación, expresado en unos "lineamientos estructurales" para el Área Metropolitana y su Región (Figura 5), inspirado en un Greater Buenos Aires Plan (1969), aunque, en rigor, no se pudiera adoptar la doctrina regional planning de Abercrombie para el Greater London Plan (1944). Planteo impracticable que reviste en no tener un marco político interjurisdiccional de los distritos involucrados; aspecto este, que ya reclamaba Della Paolera, incluso Bereterbide, en la década de 1930 cuando impulsan sus respectivas propuestas para reconocer el Gran Buenos Aires como una unidad regional de planeamiento (Buenos Aires, 1969). De todas maneras, la herencia de ese plan aparece en el Código, un instrumento legislativo sancionado en
1977 bajo el mandato de facto del Intendente Osvaldo Cacciatore, aunque con otra dirección técnica contraria al planteo original, que impuso por arriba del texto un plano con los trazados de nueve autopistas urbanas que llegarían al casco histórico de la ciudad.

Ahora bien, se ha dicho que el Código ha fracasado en la escala arquitectónica en propuestas clave como es la "manzana con pulmón central", arquetipo de la norma. Peor aún, sus pautas constructivas han dejado una impronta en la ciudad, como el privilegio del bloque de edificio de perímetro libre y su indiferencia al tejido histórico de Buenos Aires (Corti, 2008). Sin embargo, el Código ha conquistado la escala urbanística, imprimiendo en el paisaje de la ciudad la planificación funcionalista de la Carta de Atenas, de tal forma que las distintas funciones estén segregadas entre sí: la residencia, el comercio, la industria, las oficinas, la universidad... están físicamente separadas. Y aquí queda en evidencia que la conexión entre las distintas zonas propenda a que se usen medios de

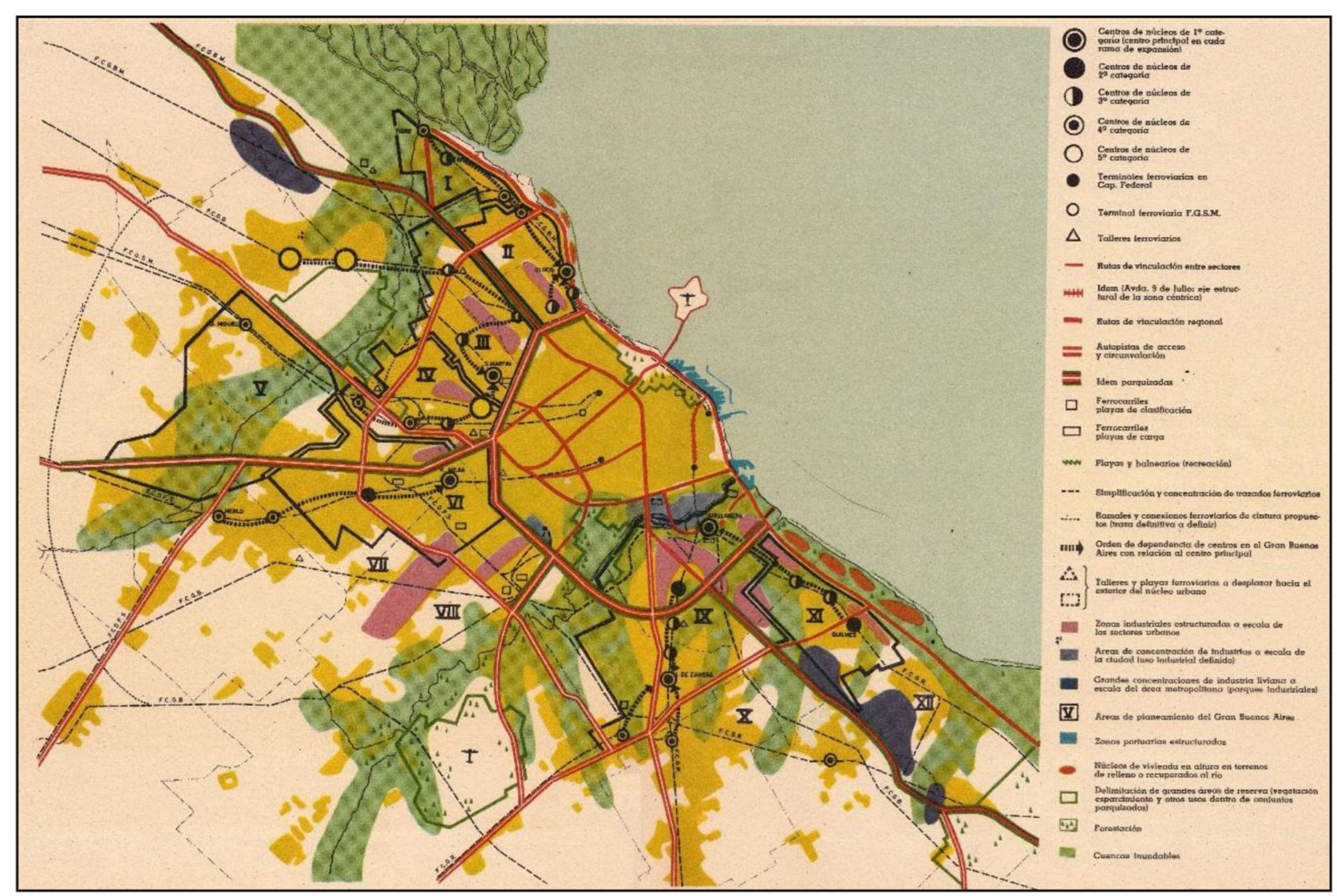

Figura 5 - Lineamientos estructurales para el Gran Buenos Aires. Plano de los lineamientos estructurales para el Gran Buenos Aires. El plan recupera diversas ideas e iniciativas previas de proyectos de Della Paolera y Le Corbusier para la ciudad, el Área Metropolitana y la Región Fuente: Plan Regulador de la Ciudad de Buenos Aires. Plano Director de Buenos Aires. Buenos Aires: Informe Preliminar. Etapa 1959-1960 (Le Corbusier et al., 1947). 
transporte automotor, uso que reclamará densas redes de autovías. Esta operación zoning se contraponía a las visiones de Della Paolera y Pastor que, desde la década de 1930, planteaban homogeneizar los suburbios de Buenos Aires para convertirlos en un todo orgánico, integral y único. Peor aún, el urbanismo funcionalista considera los suburbios como "reserva de suelo urbanizable" para viviendas, fábricas, áreas recreativas y vías de comunicación, mientras que el urbanismo organicista hace una valoración ecológica del paisaje natural y productivo: la energía solar es quien "produce la materia vegetal necesaria para la obtención de alimentos" que la misma ciudad necesita.

Y aún más, la hegemonía conceptual que a lo largo de su historia ha detentado la Capital en el plano del urbanismo tuvo una influencia notoria en la elaboración de normativas municipales similares, tanto en el conurbano bonaerense como en centenares de otras ciudades argentinas. Basta señalar la Ley 8912 de Ordenamiento Territorial de la Provincia de Buenos Aires, sancionada en 1977 en una época donde triunfa esa ideología urbanística que sigue vigente hoy en día. La otra tradición de urbanismo, que nació con Geddes y Howard, con sus vernáculos rioplatenses - organicista, regionalista, artística, anti-industrialista, historicista y, también, ecologista - permaneció más en la escala urbanística que en la arquitectónica. Y aunque esa línea de planeamiento urbano existió (y existe), fue derrotada por el imperio de la legislación urbanística de los CIAM y Le Corbusier, también generalista y topográfica pero más bien con una lectura escenográfica del marco geográfico, que prescindió de consideraciones ecológicas. Así, la tradición urbanística de Geddes-Mumford (junto con los seguidores de la ciudad-jardín), en Della Paolera-Hegemann, con Pastor y Randle - biologicista, reaccionaria y secular - también fue ecologista, tanto para bien o para mal, porque comprendía la ciudad en un contexto regional.

\section{Urbanismo ecológico}

Las últimas décadas están marcadas por un desplazamiento del urbanismo moderno, tanto funcionalista como organicista, sobre todo en el terreno arquitectónico, y también por un rechazo al planeamiento urbanístico general, fundamentalmente en lo relativo a una visión global de la ciudad en un contexto regional. Se ha producido un repliegue en la planificación de la ciudad en su conjunto, tal vez ocasionado por los nefastos acontecimientos del autoritarismo de Estado, haciendo que su vigencia se juzgue impracticable. Paradójicamente, a partir de la década de 1970, decrece en un sentido inversamente proporcional al que crecen los imperativos ecológicos en el seno de las ciudades. Irónico, porque la preocupación ecológica en la ciudad apela precisamente a una mirada general y global, es decir, en contexto de región.

Mientras tanto, triunfa el "urbanismo posmoderno", que nace precisamente como reacción al formalismo abstracto del urbanismo moderno, y se caracteriza por la mezcla de estilos, incluso, algunos de sus arquitectos más representativos - y oportunistas - se presentan con una preocupación ecológica. Pero ese urbanismo posmoderno tiene más que ver con "intervenciones" urbanas y arquitectónicas de mercado en localizaciones limitadas, concretas, puntuales, como por ejemplo la ocupación dispersiva en los suburbios en forma de urbanizaciones cerradas. Hay que señalar que el incremento de las intervenciones urbanas puntuales - por fragmentos, por partes - con el consiguiente decaimiento actual del planeamiento urbano general - regional, global -, no hace más que ocultar que el desarrollo del urbanismo argentino para el Gran Buenos Aires estuvo marcado por dos doctrinas urbanísticas bien distintas, y no solo por una. Que hubo dos planos de intervención bien diferenciables, y no uno, y que unas veces se articulaban entre sí, y muchas otras veces no.

En esos dos planos reconocemos no solo elementos ecológicos propios, sino representaciones en el paisaje que proyectan un repertorio de sentidos, los cuales han servido de fundamento para acciones en la geografía metropolitana: un plano más situacional, funcionalista (marcado por lo espacial y estratégico), como ese impulso obsesivo de las valorizaciones hacia el Río de la Plata, con la ciudad de los negocios, la capitalidad y, también, que cobran sentido con el eje de las autopistas-urbanización; y en contraposición, hubo otro plano más biológico, organicista (con énfasis en lo corporal, en lo ecológico) como la propuesta de una frontera en la pampa para frenar la conurbación, mediante la materialización de un cinturón verde, evidenciado con el despliegue de la dispersión urbana de las elites en clave de ciudad jardín. Sin embargo, en esos planos que se diferencian, como representación abstracta de la planificación general, hay una espacialidad que los encuentra: 
ambos evidenciaron profundas contradicciones, en tanto espacio para la reproducción de relaciones de producción (Lefebvre, 1974), al quedar derrotados, pulverizadas por el espacio material de la propiedad privada. Una contradicción ante, por un lado, la gran capacidad de abstracción del espacio con planes estatales a gran escala regional, mientras que, por el otro, ese espacio como tal quedó obstaculizado por la fragmentación de las propiedades y su valorización de mercado.

En particular, ese urbanismo de Le Corbusier quedó rendido en frustrados planes para Buenos Aires, a pesar de que logró expresarse en ciertos terrenos arquitectónicos como bloque de edificios, sobre todo, con los postulados impresos en la legislación que elevaron los estándares de urbanización ${ }^{8}$. Muy visible en la gentrificación del centro, con intervenciones en torre y perímetro libre, arrasando tejido urbano tradicional, especialmente patente en contextos de valor patrimonial en barrios como Caballito, Palermo o Belgrano, que se reproducen en varios centros del conurbano. De tal manera que la tradición funcionalista - geometrista, zonificadora - aparece más condensada en la escala arquitectural que en la escala urbanística de conjunto, a pesar de estar expresada en la normativa urbanística. Para la década de 1970 ya se sabía que el bloque de edificios había fracasado como "máquina de habitar" aplicable a la vivienda popular, sobre todo en relación al mantenimiento de los espacios comunes; por otro lado, también se sabía que los ensayos que intentan facilitar el acceso en automóvil a los suburbios residenciales de las ciudades también habían fracasado: las nuevas autopistas reclamaban más autos, los cuales causaban más congestión y

\footnotetext{
${ }^{8}$ En la Provincia de Buenos Aires, con la sanción del Decreto Ley Provincial no 8.912/77 en el contexto de la última dictadura cívico-militar, se reglamentó la subdivisión de la tierra, definiendo el marco normativo al cual deben ajustarse las ordenanzas municipales que regulan el uso del suelo. Esta Ley planteó una serie de restricciones a la urbanización del suelo que no esté provisto de los servicios urbanos básicos (agua, desagües cloacales, redes pluviales, electricidad, pavimentación, área verdes, equipamiento urbano entre otros) y retrajo, desde el momento en que comenzó a regir, la aprobación de nuevos loteos urbanos tradicionales, debido a dos motivos: uno es el de los altos estándares exigidos respecto de la dotación de servicios, y el otro es la cantidad de lotes aprobados antes de la sanción era tal, que hoy en día aún existen algunos que continúan baldíos (Clichevsky, 2001).
}

requerían, a su vez, más autopistas. Paralelamente, el desprecio que tuvieron durante décadas los medios de transporte público, especialmente el ferroviario - a pesar de la actual tendencia a su recuperación -, llevó a apostar por el automóvil particular que en vez de organizar el transporte metropolitano terminó congestionándolo.

La apertura de autopistas alentó la expansión de un nuevo suburbio residencial dirigido a sectores medios y altos en la forma de urbanizaciones cerradas desde las que sus habitantes se desplazan en automóvil. En el marco de este fenómeno, llegó a urbanizarse una superficie equivalente a dos veces la Ciudad de Buenos Aires $\left(500 \mathrm{~km}^{2}\right)$, en la que residen menos de 100.000 familias: un patrón de muy baja densidad demográfica, muchos sobre humedales con una alteración de servicios ecológicos de alcance regional (Fernández, 2012). En contraste, el grueso del peso demográfico de la expansión urbana se verificó sobre los ejes ferroviarios en la segunda corona metropolitana, especialmente con la ocupación informal en los intersticios ocupados por las cuencas fluviales: cerca de 900 villas y asentamientos donde viven más de un 1.000.000 de habitantes (Cravino, 2008). La invasión de terrenos vacantes (asentamientos) y su posterior regularización dominial fue la modalidad dominante en la conformación de nuevas barriadas, o, como respuesta a este, a través de conjuntos de vivienda social en la periferia, algunos sobre terrenos ambientalmente poco aptos de la geografía metropolitana.

Durante los primeros planes del Gran Buenos Aires, el organicismo fue reaccionario, muy controvertido y especialmente nefasto como explicación biologicista de fenómenos urbanos, aunque tuviera buenas razones ecológicas para su época. Aunque habría que señalar, desde una perspectiva bien diferenciada, que los argumentos de esa doctrina urbanística cobran vigencia cuando se adhiere a una "biología" en la ciudad, con sus implicaciones ecológicas: por un lado, las entradas de energía y de materiales, cuya dimensión dependerá del número de habitantes, de la ocupación del suelo y de su consumo exosomático ${ }^{9}$, y, por el otro,

\footnotetext{
${ }^{9}$ Consumo exosomático se refiere a los flujos materiales y energéticos, externos a la actividad biológica (motores a combustión, calefacción, refrigeración, construcción, acueductos, industria, etc.). Por su parte el consumo endosomático, se refiere a procesos de uso y transformación de los materiales y la energía por los organismos que conforman un ecosistema (comida, bebida de humanos y animales, fotosíntesis, residuos líquidos, sólidos o gaseosos de los animales y plantas).
} 
las salidas de basuras, o sea, de residuos sólidos, de emisiones gaseosas, de efluentes líquidos. Una vez que la ciudad alcanza cierto tamaño, es imposible llevar a la práctica esa visión "orgánica", osea, la de un medio cuyas entradas son únicamente la energía solar, los nutrientes del suelo y el agua de lluvia, puesto que depende de un entorno (Martínez Alier, 1991). De todos modos, es posible pensar en una "ecología de la ciudad", donde esos flujos de entrada y salida de materiales y energías sean distintos dependiendo de las pautas de urbanización, es decir, del tipo de organización metropolitana: modelos de transporte de personas y mercancías, tipo de explotación del agua y tratamiento de las aguas negras, sistemas de manejo de residuos, calefacción y refrigeración, maneras de construir y localizar las viviendas, etcétera.

La crítica ecológica a la Carta de Atenas, cuya doctrina separa físicamente usos y funciones de la ciudad, se basa en el argumento de que dicha separación aumenta el metabolismo urbano, porque la segregación de funciones homogéneas incrementa la construcción de vialidades y el uso de medios de transporte mecánico, de lo que depende su vinculación, especialmente apoyado en modelos urbanísticos dispersos de tipo anglosajón que se basan en el automóvil privado. La movilidad horizontal provoca un mayor consumo energético, con la consecuente disipación de calor y emisión de contaminantes atmosféricos al entorno. También induce a un mayor consumo de tierra y materiales derivado de la dispersión edilicia, causante de una simplificación de los sistemas naturales sobre los que se asientan. De tal manera que la explotación de los ecosistemas regionales y globales, junto con la contaminación de los ecosistemas locales, genera disfunciones en el modelo funcionalista de producir ciudad. De ahí la apuesta de promover una organización urbana basada en una diversidad de usos y funciones, a través de modelos de ciudades compactas y complejas, ya que son más eficientes en el consumo de la tierra y el aprovechamiento de recursos energéticos y materiales (Rueda, 2012). En efecto, la diversidad espacial de las funciones en la ciudad brinda proximidades relativas entre ellas, ofrece condiciones para optimizar la vida urbana, puesto que permite apoyarse en el transporte público y la pautas endosomáticas de movilidad, así como preservar las áreas rurales de soporte. Este planteamiento para Buenos Aires viene a recuperar muchas premisas del urbanismo organicista y supone, fundamentalmente, el privilegio de la planificación en un contexto ecológico-regional.

El suelo de los alrededores de la ciudad de nuestra geografía debería ser más valorado por su producción de materia vegetal necesaria para la alimentación y producción de proteína animal, que sea estéticamente agradable y climáticamente funcional. Los suelos del periurbano bonaerense son muy fértiles, sobre todo en el norte y el oeste, por una producción considerable de alimentos para el conjunto de la región, mientras que los suelos del sur son menos propicios para la agricultura y más para la ganadería. El problema actual es que la expansión urbana consume el suelo productivo, comprometiendo el mantenimiento de la productividad de la tierra de mayor valor social, ya que soporta la horticultura de proximidad, del que se abastece buena parte del mercado de frutas y verduras de la ciudad (Barsky, 2005). Además, hay fragmentos de áreas de gran valor natural, especialmente en el ecotono deltaico-pampeano, representativos del pastizal, la selva ribereña y el espinal, que brinda funciones como el refugio de la biodiversidad, ciclaje del agua, regulación hidrológica, reciclaje de nutrientes, entre muchas otras funciones ecosistémicas que deberían protegerse (Fernández, 2012).

La crisis actual del planeamiento urbanístico general, acaso por diversos fracasos en el plano interjurisdiccional, quedó rendida por las valorizaciones del mercado, de la mano de arquitectos-urbanistas promotores de la dispersión suburbial en enclaves cerrados, como los de Nordelta o Eidico en Tigre, incluso, contrariamente a esas expresiones urbanas, en la Capital con torres como Le Parc de Puerto Madero que sobresalen en el horizonte rioplatense para aprovecharse de las formidables plusvalías. Pero ese triunfo actual de las intervenciones por proyectos aislados, que no se inscriben en un planeamiento general de la región ecológica definida, es un triunfo de la ideología postmoderna metropolitana que privilegia la valorización parcelaria de las rentas de paisaje. Todo esto que apuntamos -aunque sintéticamenteabona la idea de pensar los temas de la planificación de la ciudad, de su organización metropolitana, en el contexto de la región. En realidad son "nuevos temas viejos" del urbanismo y la ecología para Buenos Aires. Y este último punto de nuestro recorrido muestra una pretensión analítica que el «urbanismo ecológico» viene a expresar. Especialmente cuando se asoma como un dominio de pensamiento que debe reconocer 
influencias de la historia cultural urbana, y que en la actualidad contiene diversidad de enfoques, métodos e instrumentos, incluso comprobadas aplicaciones en el campo del diseño urbanístico en diferentes realidades urbanas, con una base epistemológica común: pensar la ciudad como ecosistema. Una necesaria apuesta para que nuestras ciudades latinoamericanas afronten los problemas de acceso a la tierra, de movilidad y de desigualdad en las formas contemporáneas de producir ciudad. En todo caso, añaden a los desafíos ecológicos una evidente condición: que el urbanismo ecológico triunfará si tiene ascenso un planeamiento urbanístico general en contexto de región. Si no ocurre esto, tan solo será una victoria pírrica para las metrópolis.

\section{Referencias}

Ballent, A. (2005). Las huellas de la política: vivienda, ciudad, peronismo en Buenos Aires, 1943-1955. Buenos Aires: Prometeo.

Barsky, A. (2005). El periurbano productivo, un espacio en constante transformación. Introducción al estado del debate, con referencias al caso de Buenos Aires. Scripta Nova: Revista Electrónica de Geografía y Ciencias Sociales, 194(36). Retrieved in 17 junio 2015, from http://www. ub.es/geocrit/sn/sn-194-36.htm

Buenos Aires. Municipalidad de la Ciudad de Buenos Aires. (1925). Proyecto Orgánico para la Urbanización del Municipio. El Plano Regulador y de Reforma de la Capital Federal, Comisión de Estética Edilicia de la Intendencia Municipal de Buenos Aires Talleres Peuser. Buenos Aires.

Buenos Aires. Municipalidad de la Ciudad de Buenos Aires. (1969) Buenos Aires: master plan summary, Dirección del Plan Regulador. Buenos Aires.

Caride, H. (2013). Ciudad, urbanismo y ecología urbana. In M. Di Pace \& H. Caride. Ecología urbana. Buenos Aires: UNGS.

Clichevsky, N. (2001) Mercado de tierra y sector inmobiliario en el Área Metropolitana de Buenos Aires. In Seminario Transformaciones e impactos territoriales. Rosario: Universidad Nacional de Rosario.

Clichevsky, N., Prevot-Schapira, M. F., \& Schneier, G. (1990). Loteos populares. sector inmobiliario y gestión local en Buenos Aires. Buenos Aires: CEUR; Paris: CREDAL.
Corti, M. (2008). Odilia Suárez: cuando tuvimos plan.... Revista Café de las Ciudades, 5(49). Retrieved in 17 junio 2015, from http://www.cafedelasciudades.com.ar/cultura_49.htm Cravino, C. (2008). Los mil barrios (informales) del AMBA: aportes para la construcción de un observatorio del hábitat popular. Los Polvorines: Universidad Nacional de General Sarmiento.

Della Paolera, C. (1981). Ecological Belt of Buenos Aires Metropolitan Area. New York: American Society of Civil Engineers.

Della Paolera, C. M. (1934). El símbolo del urbanismo. Buenos Aires: Dirección del Plan de Urbanización, Municipalidad de la Ciudad de Buenos Aires.

Fernández, L. (2012). Expansión urbana y sus impactos en los servicios ecológicos en la cuenca del Río Luján. In P. A. Pintos \& P. Narodowski (Eds.), La privatopía sacrílega: efectos del urbanismo privado en humedales de la cuenca baja del Río Luján Una crítica desde la geografía urbana. Buenos Aires: Imago Mundi.

Geddes, P. (1915). Cities in evolution. London: Williams and Norgate.

Gorelik, A. (1998). La grilla y el parque. Buenos Aires: Universidad Nacional de Quilmes.

Gorelik, A. (2004). Miradas sobre Buenos Aires: historia cultural y crítica urbana. Buenos Aires: Siglo XXI Editores.

Instituto Nacional de Estadística - INDEC. (2010). Censo Nacional de Población, Hogary Vivienda 2010. Buenos Aires. Recuperado el 17 junio 2015, de www.censo2010.govar

Laura, G. (1970). La ciudad arterial: esquema para el desarrollo futuro del transporte en la ciudad de Buenos Aires. Buenos Aires: Artes Gráficas Cassese-Carrá.

Laura, G. (1978). El cinturón ecológico. Buenos Aires: CEAMSE.

Le Corbusier, J. P. (1941). Sur les quatre routes. Paris.

Le Corbusier, J. P. (1954). Carta de Atenas, edición de la Municipalidad de la Ciudad de Buenos Aires.

Le Corbusier, J. P., Kurchan, J., \& Hardoy, J. F. (1947). Plan Director para Buenos Aires. La Arquitectura de Hoy, 4, 1-53. Versión castellana de abril de 1947. Versión francesa de la L'. AA; l'Architecture d'Aujourd'Hui.

Lefebvre, H. (1974). La producción del espacio. Revista de Sociologia, 3(1), 224-230.

Liernur, J. F. (1985). La estrategia de la casa autoconstruida: secretos populares y vida urbana. Buenos Aires: CLACSO. 
Liernur, J. F. (2001). Arquitectura en la Argentina del siglo XX: la construcción de la modernidad. Buenos Aires: Fondo Nacional de las Artes.

Martínez Alier, J. (1991). Ecología y urbanismo en Barcelona. Papers, 38(1), 73-89.

Novick, A. (1992). voz “Plan”. In J. Liernur \& F. Aliata (Eds.), Diccionario histórico de arquitectura, hábitat y urbanismo en la Argentin: edición preliminar. Buenos Aires: SCA, CEADIG, IAA, FADU, UBA.

Novick, A. (2000). Planes vs. proyectos: algunos problemas constitutivos del urbanismo. Revista de Urbanismo, 3.

Novick, A. (2007) Planes realizados y proyectos inconclusos en la construcción de la ciudad moderna: Buenos Aires, 1900-1940 (Tesis doctoral). Buenos Aires: Universidad de Buenos Aires.

Oliveira, B. (1940). A casa popular e o aspecto urbanístico das cidades. Urbanismo e Viação, 3(7), 209-214.

Outtes, J. (2002). Disciplinando la sociedad a través de la ciudad: el origen del urbanismo en Argentina y Brasil (1894-1945). EURE, 28(83).

Pastor, J. (1946). Urbanismo con planeamiento, principios de una nueva técnica social. Buenos Aires: Editorial Arte y Técnica.
Randle, P. (1983). Teoría de la ciudad. Buenos Aires: Oikos.

Randle, P. (1984). Razón de ser del urbanismo. Buenos Aires: Oikos.

Rueda, S. (2012). Urbanismo ecológico. Barcelona: Agencia de Ecología urbana de Barcelona.

Segre, R. (2006). Le Corbusier: los viajes al Nuevo Mundo. Cuerpo, naturaleza y abstracción. Revista Café de las Ciudades, 5(46). Retrieved in 17 junio 2015, from http:// www.cafedelasciudades.com.ar/arquitectura_46.htm

Torres, H. (1993). El mapa social de Buenos Aires (19401990) (Serie Difusión, No. 3). Buenos Aires: Secretaría de Investigación - FADU/UBA.

Vautier, E., \& Bereterbide, F. (1932). ¿Qué es el urbanismo? Buenos Aires: Concejo Deliberante de la Ciudad de Buenos Aires.

Von Uexküll, J. (1945). Ideas para una concepción biológica del mundo (Colección Historia y Filosofía de la Ciencia). Madrid: Espasa Calpe. Con prólogo de Ortega y Gasset.

Recibido: Jun. 17, 2015

Aprobado: Sept. 3, 2015 